\title{
In Vitro Culture and Phylogenetic Analysis of "Candidatus Arsenophonus triatominarum," an Intracellular Bacterium from the Triatomine Bug, Triatoma infestans
}

\author{
VÁCLAV HYPŠA ${ }^{1}$ AND COLIN DALE ${ }^{2 *}$ \\ Institute of Parasitology, Academy of Sciences of the Czech Republic, University of South Bohemia, \\ 37005 Ceske Budejovice, Czech Republic, ${ }^{1}$ and Tsetse Research Group, Division of Molecular Genetics, \\ University of Glasgow, Glasgow G11 6NU, United Kingdom ${ }^{2}$
}

\begin{abstract}
An intracellular symbiotic bacterium was isolated from the hemolymph of Triatoma infestans and cultured in an Aedes albopictus cell line. 16S ribosomal DNA sequence analysis revealed that the bacterium was a member of the $\gamma$-3 subgroup of the class Proteobacteria, having 96.2\% sequence identity with the most closely related bacterium, Arsenophonus nasoniae, the causative agent of the son-killer trait in the parasitoid wasp Nasonia vitripennis. These bacteria share morphological features and a common tissue distribution and transmission mode. The $A$. nasoniae- $T$. infestans symbiont branch represents a lineage of insect symbionts which may be capable of horizontal transmission between phylogenetically distant host insects. We propose that the intracellular symbiont from $T$. infestans be classified as "Candidatus Arsenophonus triatominarum." The bacterium found in the hemocytes of $T$. infestans is designated the type strain of this species.
\end{abstract}

Bacteria take part in a variety of intimate symbiotic associations with insects from many different taxonomic groups $(8$, 13). Two distinct bacterial symbionts have been observed in the triatomine bug, Triatoma infestans. The first, an extracellular nocardioform actinomycete, is found in the gut of many reduviid bugs $(17,41)$, where it is known to supply B vitamins essential for host survival $(3,18,23)$. The second, originally observed in the salivary glands of $T$. infestans and Panstrongylus megistus (25), was later found to be a gram-negative bacterium capable of intracellular infection in a wide variety of $T$. infestans tissues (20). While the free-living nocardioform symbiont is easily cultivated in vitro and has been studied extensively, virtually nothing is known about the significance and taxonomic position of the intracellular symbiont. Recent attention has been focused on the possibility of using genetically modified insect symbionts to produce refractory strains of insect disease vectors $(2,5)$. Triatomine bugs, vectors of Trypanosoma cruzi, which causes Chagas' disease in humans, are ideal candidates for this novel approach to vector-borne disease control (4).

The study of intracellular insect bacteria has been complicated by the innate fastidious nature of these organisms. Until the development of a mosquito cell culture system $(37,38)$ and the introduction of in situ PCR-based phylogenetic analysis, very little was known about many of these bacteria. In the literature, the nomenclature of these organisms has proved confusing; while some are described under trivial names, others have been described under collective titles chosen on the basis of features such as morphology, host tissue distribution, and the intimacy of the bacterium-host association. This problem is illustrated by the tsetse fly (Glossina), where small endosymbionts, found in a wide variety of tissues, were originally described collectively as "rickettsia-like organisms" (32). Recent $16 \mathrm{~S}$ ribosomal DNA (rDNA) analysis has shown that

\footnotetext{
* Corresponding author. Mailing address: Tsetse Research Group, Division of Molecular Genetics, Institute of Biomedical and Life Sciences, University of Glasgow, Anderson College, 56 Dumbarton Rd., Glasgow G11 6NU, United Kingdom. E-mail: cd28y@udcf.gla.ac.uk.
}

these "rickettsia-like organisms" in fact comprise two distinct bacteria which inhabit different fly tissues and belong to different subdivisions of the class Proteobacteria (6). For convenience, these bacteria have also been described as "guest micro-organisms" (13) or "secondary (S)-endosymbionts," to provide a distinction between these multitissue symbionts and the single-cell (mycetocyte) symbionts, or "primary (P)-endosymbionts," found in insects with restricted diets. Although the mycetocyte endosymbionts of tsetse have recently been assigned correct nomenclature (1) along with mycetocyte endosymbionts from other insects (29), many insect bacteria, especially "S-endosymbionts," have retained their trivial names even after phylogenetic reconstruction.

In this study we describe the isolation and in vitro culture of an "S-endosymbiont" from the hemolymph of $T$. infestans. In addition, we show that this bacterium is present in the heart, neural ganglion, and salivary glands of $T$. infestans. $16 \mathrm{~S}$ rDNA sequence analysis and preliminary morphological characterization suggest that this bacterium is a member of the genus Arsenophonus. In the absence of phenotypic test results required for the valid description of a bacterial taxon or species we formally propose that the provisional status of Candidatus be implemented for this organism. In addition we propose the name "Candidatus Arsenophonus triatominarum."

\section{MATERIALS AND METHODS}

Electron microscopy. Electron microscopy was used to confirm the presence of bacteria in bug hemocytes prior to cultivation in vitro. Hemolymph was aspirated from a wounded $T$. infestans bug into $2.5 \%$ glutaraldehyde in $0.1 \mathrm{M}$ cacodylate buffer (CB), pH 7.2. After incubation for $20 \mathrm{~min}$ at room temperature, hemocytes were pelleted by centrifugation $(2,000 \times g, 5 \mathrm{~min})$, washed in fresh $\mathrm{CB}$, and resuspended in a molten solution of $\mathrm{CB}$ containing $2 \%$ agarose. Pieces of solidified agarose were fixed in $1 \%$ buffered osmium tetroxide at room temperature for $1 \mathrm{~h}$, dehydrated in a graded ethanol series, and embedded in an EponAraldite mixture. Ultrathin sections were prepared and examined on a Philips EM 420 microscope.

Isolation and cultivation in an insect cell line. Bacterial culture TI1 was isolated from a laboratory colony of $T$. infestans (Institute of Parasitology, Ceske Budejovice, Czech Republic) and cultivated in an Aedes albopictus cell culture. $A$. albopictus cell line C6/36 (22) was maintained in Mitsuhashi-Maramorosch (MM) medium supplemented with $20 \%$ heat-inactivated fetal calf serum (ICN Biomedicals, Ltd., Bucks, United Kingdom) at $25^{\circ} \mathrm{C}$ by passaging the cells every 10 days with a 1:10 split into fresh MM medium. Two adult $T$. infestans females 
were surface sterilized by immersion in Alcide LD (Life Science Laboratories, Basingstoke, United Kingdom) for $5 \mathrm{~min}$ and rinsed twice in sterile water. After removing a foreleg from each bug, $10 \mu l$ of hemolymph, including the hemocytes filled with symbionts (see Fig. 1), was aspirated from each bug and mixed with $200 \mu \mathrm{l}$ of MM medium. A modification of the coverslip technique (38) was used to promote infection of a confluent $A$. albopictus cell culture. Briefly, $200 \mu \mathrm{l}$ of MM-hemolymph was combined with $5 \mathrm{ml}$ of 48 -h-old $\mathrm{C} 6 / 36$ cells (cultivated on a coverslip in a flat-bottomed centrifuge tube). Cultures were centrifuged $\left(1,500 \times \mathrm{g}, 5 \mathrm{~min}, 25^{\circ} \mathrm{C}\right)$ to promote infection, maintained at $25^{\circ} \mathrm{C}$, and passaged every three days. Cultures were examined by Gimenez staining (16) and light microscopy at 4,5 , and 6 days postinoculation.

Cloning and sequencing of 16S rDNA. PCR was used to amplify a 1,361-bp fragment of the eubacterial 16S rDNA gene with conserved primers 5'-GCTTAACACATGCAAG and 5'-ACGGGCAGTGTGTACAAGACC, corresponding to positions 45 to 61 forward and 1406 to 1386 reverse in Escherichia coli $16 \mathrm{~S}$ rDNA, respectively (31). Template DNA was prepared from selected bug tissues known to be infected with bacteria (20); salivary glands, heart, and neural ganglia were removed by dissection and washed in STE buffer $(100 \mathrm{mM}$ $\mathrm{NaCl}, 10 \mathrm{mM}$ Tris- $\mathrm{HCl}, 1 \mathrm{mM}$ EDTA [pH 8.0]). These individual tissues were homogenized in $50 \mu \mathrm{l}$ of STE buffer containing proteinase $\mathrm{K}(10 \mathrm{mg} / \mathrm{ml})$. After incubation $\left(37^{\circ} \mathrm{C}, 30 \mathrm{~min}\right)$ and denaturation $\left(95^{\circ} \mathrm{C}, 5 \mathrm{~min}\right)$ debris was removed by centrifugation $(13,000 \times g, 5 \mathrm{~min})$ and the supernatant was retained for PCR. One-microliter samples of culture fluid were used as templates in PCRs to detect the presence of bacteria in $A$. albopictus cell cultures. Culture fluid from three uninfected $A$. albopictus cell cultures was used to provide negative controls for PCR. Individual reactions were carried out in $50 \mathrm{ml}$ of thermostable polymerase buffer (Promega, Southampton, United Kingdom) containing $1.5 \mathrm{mM} \mathrm{MgCl}, 0.2$ $\mathrm{mM}$ deoxynucleoside triphosphates, $1 \mathrm{U}$ of Taq DNA polymerase (Promega) and $50 \mathrm{pmol}$ of each primer. Reaction conditions consisted of an initial 5-min denaturation step $\left(94^{\circ} \mathrm{C}\right)$ followed by 30 cycles of denaturation $\left(94^{\circ} \mathrm{C}, 1 \mathrm{~min}\right)$, annealing $\left(55^{\circ} \mathrm{C}, 1 \mathrm{~min}\right)$, and extension $\left(72^{\circ} \mathrm{C}, 1 \mathrm{~min}\right)$. A 10 -min extension step $\left(72^{\circ} \mathrm{C}\right.$ ) was included at the end of the PCR program to promote A-tailing of PCR products. After electrophoresis and visualization, the 1,361-bp fragment from each reaction was excised and removed from gel slices by electroelution into dialysis tubing. Following dialysis and concentration in Ultrafree MC filters (Millipore), the fragments were cloned into pGEM T vector (Promega) according to the manufacturer's instructions. Recombinant clones were identified by analysis of SacII/PstI-restricted plasmid DNA, and positive clones were sequenced by the chain termination method on an ABI automated sequencer (Applied Biosystems, Inc.). Eight clones (two from each tissue type and two from infected $A$. albopictus cell cultures) were each sequenced on both DNA strands by using T7/SP6 primers and two internal primers (5'-TAGGTGGGG TAAAGGCTCAC and 5'-GTCTCAGCGCTCCCGAAGG).

Phylogenetic analysis. The 1,361-bp 16S rDNA consensus sequence was used for phylogenetic analysis alongside other eubacterial sequences, selected according to a Ribosomal Database Project (26) maximum similarity search. All sequences were aligned by a clustal algorithm with MEGALIGN (LASERGENE; DNASTAR Inc., Madison, Wis.), and regions of confident alignment were analyzed with the PHYLIP package (14). The maximum parsimony tree was obtained by heuristic parsimony analysis (Dnapars program). To determine bootstrap support, 1,000 sets of data were generated (Seqboot program) and analyzed for maximum parsimony (Dnapars program), and the consensus tree and bootstrap values were obtained (Consense program). Sequence similarities were determined by MEGALIGN with the Wilbur-Lipman algorithm. Pairwise evolutionary distances were calculated using a Kimura 2 parameter model (Dnadist program).

Nucleotide sequence accession numbers. The GenBank accession numbers for the $16 \mathrm{~S}$ rDNA sequences used in this study are as follows: Legionella pneumophila, M36026; "P-endosymbiont" of Glossina austeni, L37340; "P-endosymbiont" of Acyrthosyphon pisum, M27039; Proteus vulgaris, J01874; Arsenophonus nasoniae. M90801; TI1, U91786 (this study); Photorhabdus luminescens, D78004; Xenorhabdus beddingii, D78006; "S-endosymbiont" of Glossina austeni, U64869; Enwinia amylovora, X83265; E. coli, X800731; Salmonella typhimurium, X80681; endosymbiont of Cimex lectularius, U65654; endosymbiont of Euscelidius variegatus, Z14096; "S-endosymbiont" of A. pisum, M27040; Serratia marcescens, M59160.

\section{RESULTS AND DISCUSSION}

Electron microscopy. Electron microscopy was used to examine hemocytes isolated from $T$. infestans prior to cultivation in an A. albopictus cell line (Fig. 1). Pleomorphic and predominantly rod-shaped bacteria were observed in the cytoplasm of these cells. Morphologically, these bacteria were similar to those observed previously in hemocytes (21) and in other $T$. infestans tissues (20).

Culture of strain TI1. A. albopictus cell cultures inoculated with $T$. infestans hemolymph displayed the first signs of bacterial infection after $72 \mathrm{~h}$ at $25^{\circ} \mathrm{C}$. Bacterial culture TI1, detected

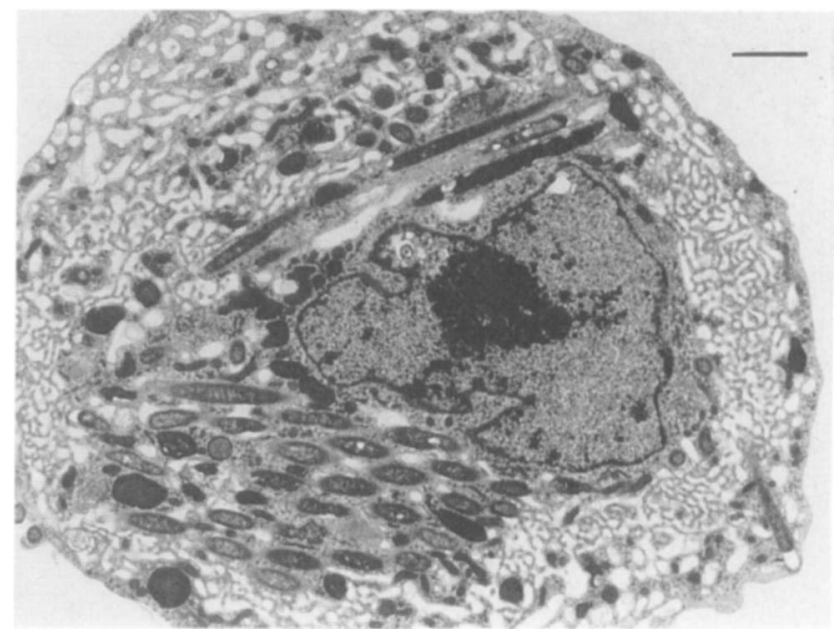

FIG, 1. Electron micrograph of a TI1-infected hemocyte from $T$. infestans. Note the pleiomorphic nature of these organisms. Bar $=1 \mu \mathrm{m}$.

by staining and light microscopy, was associated exclusively with the outer membranes of host cells. After $96 \mathrm{~h}$, large clusters of TI1 were attached to host cell membranes and bacteria were visible in the cytoplasms of host cells (Fig. 2). By $120 \mathrm{~h}$ postinoculation, there was extensive intracellular infection causing some host cells to lyse, leaving nests of TI1 (Fig. 3). During attachment to insect cells and after lysis (Fig. 4), bacteria exhibited clustering and unipolar agglutination. This phenomenon has been observed with cultures of the plant symbiont Bradyrhizobium japonicum, and agglutination between bacterial cells and soybean cells is known to be mediated by a lactose-specific lectin (24). Specific processes of host cell adhesion and invasion are characteristic of many intracellular microorganisms. In the case of TI1, the timing of adhesion, invasion, and eventual lysis of the host cell is similar to that observed with the "S-endosymbionts" of the tsetse fly (35). The TI1 isolate described in this study was maintained in continuous $A$. albopictus cell culture for 3 months (involving 22 passages into fresh $\mathrm{C} 6 / 36$ cultures). TI1 retained viability throughout this time, providing passages were conducted before the 10th day after host cell lysis. After this time, any attempts to infect a fresh flask of $A$. albopictus cells were unsuccessful,

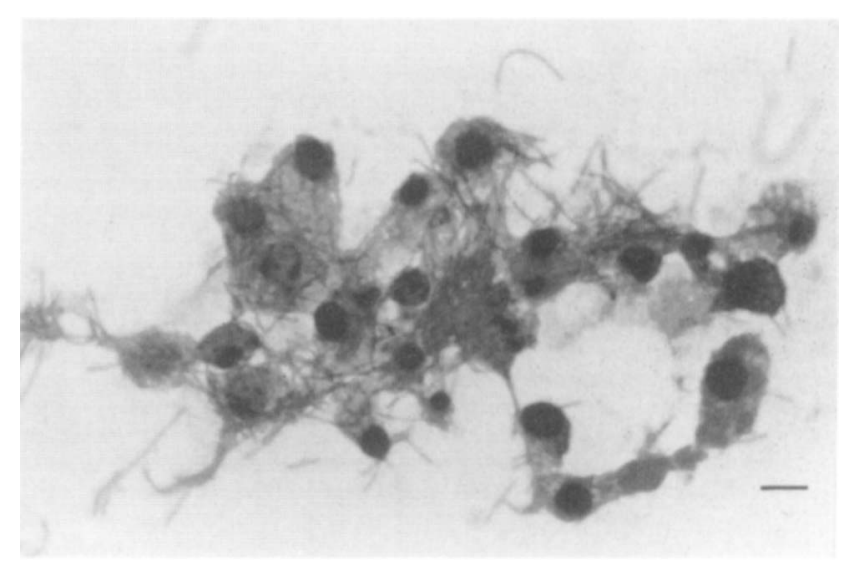

FIG. 2. Light micrograph of TI1-infected A. albopictus cells at $96 \mathrm{~h}$ postinfection. The endosymbionts are arranged in a mycelium-like network, showing extensive agglutination and attachment to host insect cells. Bar $=5 \mu \mathrm{m}$. 


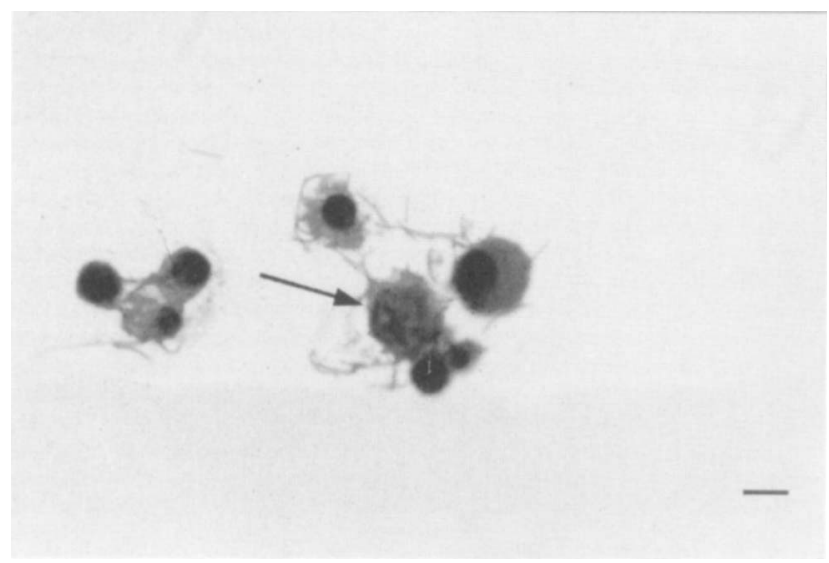

FIG. 3. Light micrograph of TI1-infected $A$, albopictus cells at $120 \mathrm{~h}$ postinfection. At this time there is extensive intracellular infection and in some cases the insect cells have lysed, leaving a cell-shaped nest of symbionts (arrow). Bar = $5 \mu \mathrm{m}$.

regardless the size of inoculum used. At 10 days after host cell lysis, TI1 cells started to drop out of suspension and form a film at the base of the culture flask. Reminiscent of bacteriophagemediated lysis, this feature has also been observed with tsetse "S-endosymbionts," which have a limited life-span in axenic culture (37). Bacteriophage-like particles have been detected in the cells of tsetse "S-endosymbionts" (35) and in T. infestans endosymbionts (20), although their role has yet to be determined. Despite many attempts, we were unable to cultivate TI1 in the absence of $A$. albopictus cells. Axenic cultivation in a range of bacteriological media, including the medium used for cultivation of $A$. nasoniae (15), was unsuccessful. Cryopreservation of TI1 also failed; cells frozen in MM containing a range of glycerol concentrations ( 10 to $20 \%$ ) could not be used to infect an $A$. albopictus cell culture.

The cultivation of TI1 in vitro may be an important step towards the production of refractory strains of $T$. infestans unable to transmit $T$. cruzi. The nocardioform symbionts of a closely related bug, Rhodnius prolixus, have already been transformed in vitro and successfully introduced into antibiotictreated aposymbiotic bugs (4). Nocardioform symbionts are transmitted by an oral-fecal route in triatomine bugs, and inheritance of the symbiont depends upon fecal contamination

FIG. 4. Light micrograph of TI1-infected $A$. albopictus cells at $144 \mathrm{~h}$ postinfection. Host cells have lysed and agglutination is less extensive. Bar $=5 \mu \mathrm{m}$.

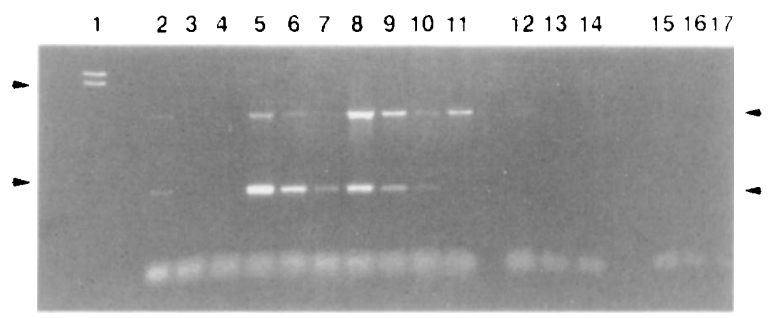

FIG. 5. PCR analysis of DNA prepared from $T$. infestans tissues and $A$. albopictus cell cultures infected with strain TI1. Lane 1, HindIII-digested lambda DNA marker; lanes 2 to 4 , heart tissue DNA (undiluted, diluted 1:10, and diluted $1: 100$, respectively); lanes 5 to 7 , salivary gland tissue DNA (undiluted, diluted $1: 10$, and diluted 1:100, respectively); lanes 8 to 10 , neural ganglion tissue DNA (undiluted, diluted 1:10, and diluted 1:100, respectively); lanes 11 to $13, A$. albopictus-TI1 culture fluid (1- $\mu$ l template, $0.1-\mu l$ template, and $0.01-\mu l$ template, respectively); lanes 14 to 16 ; uninfected $A$. albopictus culture fluid $(1-\mu 1$ template, $0.1-\mu$ l template, and $0.01-\mu$ l template, respectively); lane 17 , no template DNA. Right-side arrows, expected 1,361-bp PCR product (upper arrow) and unexpected (approximately 480-bp) PCR product (lower arrow); left-side arrows, lambda HindIII markers of 2,027 bp (upper arrow) and 564 bp (lower arrow).

of larvae. TI1 is transmitted transovarially to offspring and offers the prospect of a stable platform for the expression of antiparasitic products in a vector of medical importance. In the tsetse fly, "S-endosymbionts" are known to promote susceptibility to infection with African trypanosomes (27, 36). As yet no studies have been carried out to determine the effect, if any, of TI1 on the transmission of trypanosomes by $T$. infestans.

$16 S$ rDNA sequence analysis. PCR was used to confirm the presence of eubacteria in $A$. albopictus-TI1 cultures and in three $T$. infestans tissues (Fig. 5). In each case the expected $16 \mathrm{~S}$ rDNA amplification product (1,361-bp) was observed after electrophoresis. An additional unexpected 480-bp fragment, probably resulting from aberrant primer annealing and amplification of $T$. infestans DNA, was present only when tissue DNA was used as the PCR template. Sequencing revealed that the 16S rDNA amplification products obtained from TI1- $A$. albopictus cell culture fluid and from tissues were identical, confirming that the bacterium obtained in culture was the same organism found in the tissues of $T$. infestans. Comparison of a consensus sequence with $16 \mathrm{~S}$ rDNA sequences from other selected eubacteria revealed that TI1 was a member of the $\gamma-3$ subdivision of the class Proteobacteria, a group containing many other insect symbionts, including the symbionts of aphids, weevils, whiteflies, and tsetse $(1,6,9,11,31,34)$. The phylogenetic tree (Fig. 6) shows that TI1 is most closely related to $A$. nasoniae, the causative agent of the son-killer trait in the parasitoid wasp Nasonia vitripennis $(15,39)$. The high $16 \mathrm{~S}$ rDNA sequence identity $(96.2 \%)$ between TI1 and $A$. nasoniae suggest that TI1 may a member of the genus Arsenophonus. Proteus vulgaris, a free-living bacterium, is the next closest known relative of strain TI1, having $94.1 \%$ sequence identity.

A novel lineage of insect bacteria. The phylogenetic tree constructed with data from TI1 and selected other eubacteria (Fig. 6) shows that TI1 and $A$. nasoniae form a distinct lineage of bacteria within the family Enterobacteriaceae. A close phylogenetic relationship between bacterial symbionts from phylogenetically distant hosts usually indicates some form of horizontal symbiont transfer. The Wolbachia group, a cluster of closely related $\alpha$-Proteobacteria which cause postzygotic reproductive incompatibility in insects $(30)$, provide a good example of this phenomenon. These bacteria infect a wide range of insect hosts, including parasitoid wasps of the genus Nasonia. The genus Nasonia (Pteromalidae) comprises specialized parasitoids of cyclorhaphous diptera which infect and parasitize 


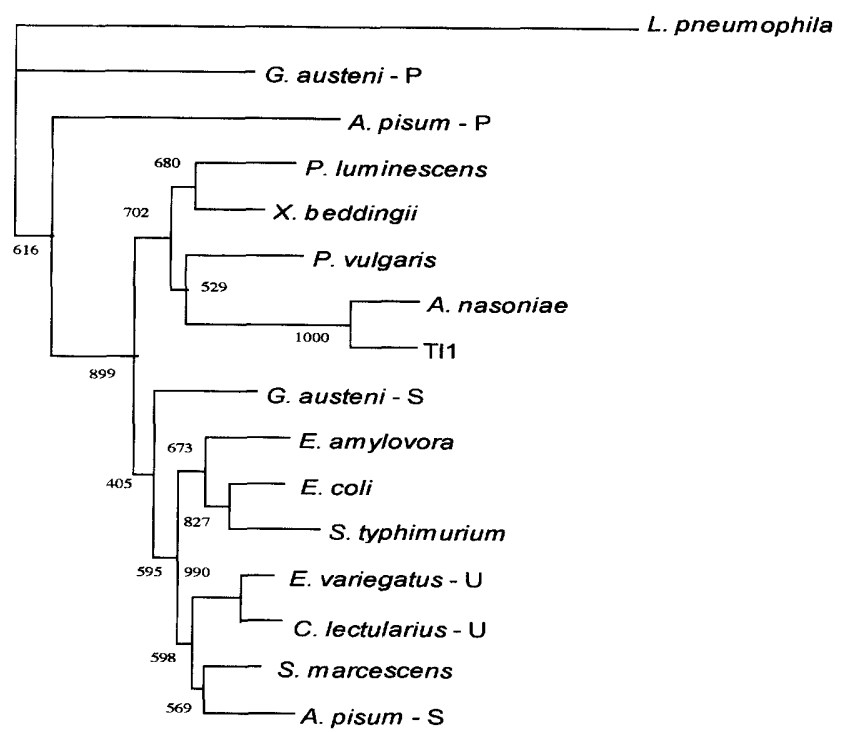

FIG. 6. Phylogenetic tree based on the 16S rDNA sequences of selected free-living and insect-borne members of the family Enterobacteriaceae. With the exception of $L$. pneumophila, $P$. luminescens, $X$. beddingii, $P$. vulgaris, $A$. nasoniae, $E$. amylovora, E. coli, S. typhimurium, S. marcescens, and TI1, the names shown are the insect species which harbor the endosymbionts. The suffix $\mathrm{P}$ denotes a primary endosymbiont, $\mathrm{S}$ denotes a secondary endosymbiont, and $\mathrm{U}$ denotes an unclassified symbiont. Bacterial strains and abbreviations $L$. pneumophila, Legionella pneumophila Dallas-1E; G. austeni, Glossina austeni; A. pisum, Acyrthosiphon pisum; $P$. luminescens, Photorhabdus luminescens ATCC 29304; $X$ beddingii, Xenorhabdus beddingii DSM 4764; P. vulgaris, Proteus vulgaris IFAM 1731; A. nasoniae, Arsenophonus nasoniae SK 14; TI1, "Candidatus Arsenophonus triatominarum" sp. nov.; E. amylovora, Erwinia amylovora Ea $7 / 74 ;$ E. coli, Escherichia coli $\mathrm{PK} 3 ; S$. typhimurium, Salmonella typhimurium ATCC $13311 ; E$. variegatus, Euscelidius variegatus; C. lectularius, Cimex lectularius; S. marcescens, Serratia marcescens ATCC 13880 . The number next to each node indicates the level of the bootstrap support.

specific host insects (12). In some parasitoid-host combinations it has been shown that Wolbachia organisms found in host and parasitoid show a significant degree of relatedness, suggesting that parasitoids may act as vehicles for the intertaxon transmission of Wolbachia (40). The intimate contact witnessed during the development of the parasitoid in the host insect body (19) certainly provides an opportunity for the transfer of bacteria. Although $N$. vitripennis is not parasitic on $T$. infestans, it is possible that ancestors of $N$. vitripennis or natural parasitoids of $T$. infestans may have acted as vehicles for the intertaxon transmission of endosymbiotic bacteria such as TI1. While there are reports of wasps of the family Pteromalidae parasitizing the reduviid bugs of South America (7), we have been unable to locate any for study. The genus Nasonia is a complex of species estimated to have diverged during the Pleistocene era, which ended around 10,000 years ago (10). By comparing aphid "P-endosymbiont" $16 \mathrm{~S}$ rDNA substitution frequencies and insect host divergence times (obtained from biogeographical records and the paleontological record) in a range of long-term speciated aphids, it has been possible to derive an accurate substitution rate for the $16 \mathrm{~S}$ rDNA locus (28). Assuming that a comparable substitution frequency $(0.01$ to 0.02 per site per 50 million years [28]) exists for other insect symbionts, it is likely that TI 1 and $A$. nasoniae diverged 36 to 72 million years ago, long before the divergence of the Nasonia complex. These data suggest that any transfer between a parasitoid and $T$. infestans must have taken place either via an ancestor of Nasonia or via a different parasitoid species. While the link between TI1 and $A$. nasoniae is intriguing, the possi- bility of intertaxon transmission of these bacteria via parasitoids remains hypothetical.

Like several other symbiotic microorganisms, $A$. nasoniae induces a sex ratio distortion in its insect host (39). The male egg lethality trait, observed in approximately $5 \%$ of wild $N$. vitripennis (33), enhances maternal transmission of $A$. nasoniae through the parasitoid host. Although strain TI1 is also maternally transmitted, we have not observed sex ratio distortion in our laboratory colony of $T$. infestans. $A$. nasoniae and TI1 share certain features which distinguish these two organisms from other bacteria found in insects. One striking feature is the widespread distribution of these bacteria through a wide variety of host tissues $(19,20)$. Both organisms are found in the host central nervous system tissue where they form large nests of infection in the brain and neural ganglia. While TI1 infection is limited to the superficial layers, neurilemma and glial cells, $A$. nasoniae are also found infecting the neuropil. The highly filamentous forms of TI1 observed in A. albopictus cell cultures (Fig. 2 through 4 ) and the embryonal gut of $T$. infestans (20) are typical of early cultures of $A$. nasoniae (15). On the basis of the high $16 \mathrm{~S}$ rDNA sequence similarity and morphological similarities between TI1 and $A$. nasoniae, we propose the name "Candidatus Arsenophonus triatominarum" for the "S-endosymbiont" of $T$. infestans, described as culture TI1 in this study. This bacterium is assigned the provisional status of Candidatus, as the phenotypic tests required for its valid description could not be performed by the culture methods outlined in this study.

Description of "Candidatus Arsenophonus triatominarum." For the features outlined in this study, the description of "Candidatus Arsenophonus triatominarum" (tri'a.to'min.a.rum. N. L. Triatominae, subfamily of reduviid bugs; triatominarum, of the Triatominae) is in agreement with the description for the genus Arsenophonus (15). Cells are nonmotile, non-sporeforming, nonflagellated, highly filamentous rods $(>15 \mu \mathrm{m}$ in length, 1 to $1.5 \mu \mathrm{m}$ in diameter) which divide by septation. Bacteria are gram negative and retain carbol fuchsin during Gimenez staining. They grow intracellularly in $A$. albopictus cell culture and cannot be cultivated in cell-free MM medium. On the basis of their $16 \mathrm{~S}$ rDNA sequence, these bacteria, along with $A$. nasoniae, form a distinct lineage within the $\gamma-3$ subdivision of the Proteobacteria. In the absence of a method for cryopreserving TI1 for deposition, we designate the intracellular endosymbiont from $T$. infestans the type strain for "Candidatus Arsenophonus triatominarum." "Candidatus Arsenophonus triatominarum" is found in the following $T$. infestans tissues: hemolymph, heart, salivary glands, neural ganglion, visceral muscles, nephrocytes, ovaries, testes, and dorsal vessels. The bacterium lives in the cytoplasm of host cells and displays pleiomorphy with forms ranging from spherical to highly filamentous.

\section{ACKNOWLEDGMENTS}

We acknowledge financial support from the Overseas Development Administration of the government of the United Kingdom through the ODA/RNRRS Animal Health Programme (C.D.) and grants A6022504 from the grant agency of the Academy of Sciences of the Czech Republic and 204/95/0271 from the grant agency of the Czech Republic (V.H.).

We thank B. L. Cohen for helpful comments during the preparation of the manuscript.

\section{REFERENCES}

1. Aksoy, S. 1995. Wigglesworthia gen. nov. and Wigglesworthia glossinidia sp. nov., taxa consisting of the mycetocyte-associated, primary endosymbionts of tsetse flies. Int. J. Syst. Bacteriol. 45:848-851.

2. Aldhous, P. 1993. Bacteria may provide access to the tsetse fly. Science 261:548. 
3. Baines, S. 1956. The role of the symbiotic bacteria in the nutrition of Rhodnius prolixus (Hemiptera). J. Exp. Biol. 33:533-541.

4. Beard, C. B., P. Mason, S. Aksoy, R. B. Tesh, and F. F. Richards. 1992. Transformation of an insect symbiont and expression of a foreign gene in the Chagas' disease vector Rhodnius prolixus. Am. J. Trop. Med. Hyg. 46:195200 .

5. Beard, C. B., S. L. O'Neill, R. B. Tesh, F. F. Richards, and S. Aksoy. 1993. Modification of arthropod vector competence via symbiotic bacteria. Parasitol. Today 9:179-183.

6. Beard, C. B., S. L. O'Neill, P. Mason, L. Mandelco, C. R. Woese, R. B. Tesh, F. F. Richards, and S. Aksoy. 1993. Genetic transformation and phylogeny of bacterial symbionts from tsetse. Insect Mol. Biol. 1:123-131.

7. Bequaert, J. 1912. L'instinct maternal chez Rhinocoris albopictus. Sign. Rev. Zool. Bot. Afr. 1:193-196.

8. Buchner, P. 1965. Endosymbiosis of animals with plant microorganisms. Interscience, New York, N.Y.

9. Campbell, B. C., T. S. Bragg, and C. E. Turner. 1992. Phylogeny of symbiotic bacteria of four weevil species (Coleoptera: Curculionidae) based on analysis of 16S ribosomal DNA. Insect Biochem. Mol. Biol. 22:415-421.

10. Campbell, B. C., J. D. Steffen-Campbell, and J. H. Werren. 1993. Phylogeny of the Nasonia species complex (Hymenoptera: Pteromalidae) inferred from an internal transcribed spacer (ITS2) and 28S rDNA sequences. Insect Mol. Biol. 2:225-237.

11. Clark, A., L. Baumann, M. A. Munson, P. Baumann, B. C. Campbell, J. E. Duffus, L. S. Osborne, and N. A. Moran. 1992. The eubacterial endosymbionts of whiteflies (Homoptera: Aleyrodoidea) constitute a lineage distinct from the endosymbionts of aphids and mealybugs. Curr. Microbiol. 25:119 123

12. Darling, D. C., and J. H. Werren. 1989. Biosystematics of Nasonia (Hymenoptera: Pteromalidae): two new species reared from birds' nests in North America. Ann. Entomol. Soc. Am. 83:352-370.

13. Douglas, A. E. 1989. Mycetocyte symbiosis in insects. Biol. Rev. 64:409-434.

14. Felsenstein, J. 1995. PHYLIP (phylogeny inference package), version 3.57c. Department of Genetics, University of Washington, Seattle.

15. Gherna, R. L., J. H. Werren, W. Weisburg, R. Cote, C. R. Woese, L. Mandelco, and D. Brenner. 1991. Arsenophonus nasoniae gen. nov., sp. nov., the causative agent of the son-killer trait in the parasitic wasp Nasonia vitripennis. Int. J. Syst. Bacteriol. 41:563-565.

16. Gimenez, D. 1964. Staining rickettsiae in yolk-sac cultures. Stain Technol. 39:135-140.

17. Goodchild, A. J. P. 1955. The bacteria associated with Triatoma infestans and some other species of Reduviidae. Parasitology 45:441-448.

18. Hill, P. 1975. Ph.D. thesis. Edinburgh University, Edinburgh, United Kingdom.

19. Huger, A. M., S. W. Skinner, and J. H. Werren. 1985. Bacterial infection associated with the son-killer trait in the parasitoid wasp Nasonia (= Mormoniella) vitripennis (Hymenoptera: Pteromalidae). J. Invertebr. Pathol. 46: 272-280.

20. Hypsa, V. 1993. Endocytobionts of Triatoma infestans: distribution and transmission. J. Invertebr. Pathol. 61:32-38.

21. Hypsa, V., and L. Grubhoffer. Two hemocyte populations in Triatoma infestans: ultrastructure and lectin-binding characteristics. Folia Parasitol. (Ceske Budejovice) 44:62-70

22. Igarashi, A. 1978. Isolation of Singh's Aedes albopictus cell clone sensitive to dengue and chikungunya viruses. J. Gen. Virol. 40:531
23. Lake, P., and W. G. Friend. 1968. The use of artificial diets to determine some of the effects of Nocardia rhodnii on the development of Rhodnius prolixus. J. Insect Physiol. 14:543-562.

24. Loh, J. T., S. C. Ho, A. W. de Feijter, J. L. Wang, and M. Schindler. 1993 Carbohydrate binding activities of Bradyrhizabium japonicum: unipolar localisation of the lectin BJ38 on the bacterial cell surface. Proc. Natl. Acad. Sci. USA 90:3033-3037.

25. Louis, C., L. Drif, and C. Vago. 1986. Mise en évidence et étude ultrastructurale de procaryotes de type rickettsien dans les glandes salivaires des Triatomidae (Heteroptera). Ann. Soc. Entomol. Fr. 22:153-162.

26. Madiak, B. L., N. Larsen, M. J. McCaughey, R. Overbeek, G. J. Olsen, K. Fogel, J. Blandy, and C. R. Woese. 1994. The Ribosomal Database Project. Nucleic Acids Res. 22:3485-3487.

27. Maudlin, I., and S. C. Welburn. 1988. Tsetse immunity and the transmission of trypanosomiasis. Parasitol. Today 4:109-111.

28. Moran, N. A. M. A. Munson, P. Baumann, and H. Ishikawa. 1995. A molecular clock in endosymbiotic bacteria is calibrated using the insect hosts. Proc. R. Soc. Lond. B 253:167-171.

29. Munson, M. A., P. Baumann, and M. B. Kinsey. 1991. Buchnera gen. nov. and Buchnera aphidicola sp. nov., a taxon consisting of the mycetocyteassociated, primary endosymbionts of aphids. Int. J. Syst. Bacteriol. 41:566568.

30. O'Neill, S. L., R. Giordano, A. M. E. Colbert, L. Karr, and H. M. Robertson. 1992. 16S rDNA phylogenetic analysis of bacterial endosymbionts associated with cytoplasmic incompatibility in insects. Proc. Natl. Acad. Sci. USA 89: 2699-2702.

31. O'Neill, S. L., R. H. Gooding, and S. Aksoy. 1993. Phylogenetically distant symbiotic microorganisms reside in Glossina midgut and ovary tissues. Med. Vet. Entomol. 7:377-383.

32. Pinnock, D. E., and R. T. Hess. 1974. The occurence of intracellular rickettsia-like organisms in the tsetse flies, Glossina morsitans, G. fuscipes, $G$. brevipalpis and G. pallidipes. Acta Trop. 31:70-79.

33. Skinner, S. W. 1983. Ph.D. thesis. University of Utah, Salt Lake City.

34. Unterman, B. M., P. Baumann, and D. L. McLean. 1989. Pea aphid symbiont relationships established by analysis of 16S rRNAs. J. Bacteriol. 171:29702974.

35. Welburn, S. C. 1991. Ph.D. thesis. University of Bristol, Bristol, United Kingdom.

36. Welburn, S. C., and I. Maudlin. 1991. Rickettsia-like organisms, puparial temperature and susceptibility to trypanosome infection in Glossina morsitans. Parasitology 102:201-206.

37. Welburn, S. C., and C. Dale. 1997. Isolation and culture of tsetse secondary endosymbionts, p. 547-554. In J. M. Crampton, C. B. Beard, and C. Louis (ed.), The molecular biology of insect disease vectors. Chapman and Hall, London, United Kingdom.

38. Welburn, S. C., I. Maudlin, and D. S. Ellis. 1987. In vitro cultivation of rickettsia-like organisms from Glossina spp. Ann. Trop. Med. Parasitol. 81:331-335

39. Werren, J. H., S. W. Skinner, and A. M. Huger. 1986. Male-killing bacteria in a parasitic wasp. Science 231:990-992.

40. Werren, J. H., W. Zhang, and L. R. Guo. 1995. Evolution and phylogeny of Wolbachia: reproductive parasites of arthropods. Proc. R. Soc. Lond. B 261:55-71.

41. Wigglesworth, V. B. 1936. Symbiotic bacteria in a blood-sucking insect, Rhodnius prolixus Stahl (Hemiptera, Triatominae). Parasitology 28:284-289. 